\title{
Long term results of treatment of vascular malformations of the gastrointestinal tract by Neodymium Yag laser photocoagulation
}

\author{
P RUTGEERTS, F VAN GOMPEL, K GEBOES, G VANTRAPPEN, \\ L BROECKAERT, AND G COREMANS
}

From the University Hospital, Department of Medicine, Division of Gastroenterology, Leuven, Belgium

SUMmaRY The effect of Yag laser photocoagulation on the course of bleeding of gastrointestinal vascular malformations was studied in 59 patients, with a total of 482 lesions. The lesions were located in the upper gastrointestinal tract alone in 25 patients, in the lower tract alone in 31 patients and in both the lower and the upper gastrointestinal tract in three patients. In the month before laser therapy the number of bleeding episodes averaged $1.09 \pm 0.6(\mathrm{SD})$ per patient $(n=57)$ and the transfusion requirements $2.4 \pm 2.6$ red blood cells units per patient, while in the month after treatment the bleeding incidence averaged $0.16 \pm 0.5$ and the transfusion requirements $0 \cdot 21 \pm 0 \cdot 8$ (both $\mathrm{p}<0.001$ ). Long term results were analysed considering for each patient an equally long pretreatment and follow up period. After a mean follow up period of 11.5 months (1-48 months), 17 of the 57 patients available for follow up rebled. The reduction of the bleeding rate was statistically significant at one, six, 12 , and 18 months of follow up, while transfusion rate was significantly decreased at one, six, and 12 months. The results were disappointing in patients with Osler-Weber-Rendu $(n=4)$ and in patients with angiomas associated with Von Willebrand's disease $(n=3)$, who all rebled. In angiodysplasia the treatment was successful in $82 \%$ of the 49 patients. The more numerous the lesions, the less effective the reduction in bleeding rate by laser treatment was. Histological studies showed that the haemostatic effect of Yag laser photocoagulation was obtained by destruction of the lesion. Rebleeding was due to lesions missed at the first treatment, incompletely treated lesions and recurrence of new lesions. In two patients a free caecal perforation necessitated a right hemicolectomy. In both patients numerous or very large lesions had been treated in the caecum.

Vascular malformations of the gastrointestinal tract are a rare, but important cause of recurrent, occasionally severe, gastrointestinal bleedings. Surgery, even when carried out after demonstration of the vascular abnormality by angiography or colonoscopy has not been very successful in the management of these lesions because of the high mortality $(7 \%)$ and a recurrence rate of at least $10 \%{ }^{1-3}$ necessitating repeated resections and an important morbidity after bowel or stomach resections. Other therapeutic methods are presently being studied to prevent bleeding from vascular

Address for correspondence: Professor G. Vantrappen, Department of Medicine and Division of Gastroenterology. Academisch Ziekenhuis, SintRafeal, Herestraat 49, Leuven 3030 Belgium.

Received for publication 9 July 1984 malformations. Selective arteriographic embolisation $^{4}$ has been advocated and may be suitable for the treatment of lesions that cannot be reached or visualised endoscopically. Endoscopic methods of treatment include monopolar and bipolar ${ }^{5-7}$ electrocoagulation, Argon- ${ }^{89}$ and Yag laser ${ }^{10}$ photocoagulation and injection therapy. ${ }^{11}$ Experience with these methods is limited and only short term results have been published. It is obvious that these methods have to be evaluated by long term follow up in a large number of patients in order to determine the indications and the limitations of these treatment modalities.

We report on the results of Neodymium Yag laser photocoagulation of 482 vascular malformations of the gastrointestinal tract in 59 patients. 


\section{Methods}

\section{PATIENTS}

From January 1979 to July 1983 vascular malformations were diagnosed in 87 patients. The aetiological diagnosis of the lesions is summarised in Table 1. Three patients with angiodysplasia-like lesions were listed as congenital arteriovenous malformations according to the classification of Moore $^{12}$ as they were so young $(15,27$ and 38 years), that the lesions were more likely to be of congenital rather than of acquired nature. Of the 87 patients, 59 could be treated by laser. Twenty eight patients were not treated for different reasons - that is, too extensive lesions in 10 patients with diffuse capillary or cavernous haemangiomas, too numerous lesions (more than 100) in four patients with Weber-Osler-Rendu and congenital arteriovenous malformations. Other exclusion criteria were: absence of previous haemorrhage $(n=10)$, patient refusal $(n=2)$, technical feasability $(n=1)$. In one patient angiodysplasia had been shown clearly at arteriography but a mucosal component of the lesion could not be detected at repeated colonoscopies.

The 59 patients treated by laser include 18 women and 41 men, with a mean age of 67.5 years (range 15-85 years). Three patients had already been submitted to surgery for bleeding from vascular malformations. Associated diseases included valvular heart disease in seven patients, arteriosclerotic heart disease in 12 patients, chronic obstructive lung disease in four patients, chronic renal insufficiency in three, and liver cirrhosis in one patient.

The diagnosis of the vascular malformations was based on the typical endoscopic aspect at repeated diagnostic endoscopies with photographs. Biopsies of the lesions were not taken routinely to avoid bleeding. Patients in whom the diagnosis was

Table 1 Vascular malformations of the GI tract: aetiological diagnosis in 87 patients

\begin{tabular}{lll}
\hline & $\begin{array}{l}\text { Patients } \\
\text { (no) }\end{array}$ & $\begin{array}{l}\text { Patients } \\
\text { treated } \\
\text { by laser }\end{array}$ \\
\hline Angiodysplasia of colon & $36(41 \%)$ & 30 \\
Angiodysplasia of colon and upper GI tract & $3(3 \%)$ & 3 \\
Angiodysplasia of upper GI tract & $24(28 \%)$ & 18 \\
Angiomas associated with & $3(3 \%)$ & 3 \\
$\quad$ Von Willebrand's disease & $8(9 \%)$ & 4 \\
Osler-Weber-Rendu & $3(3 \%)$ & 1 \\
Congenital AV malformation (Moore) & $3(3 \%)$ & 0 \\
Capillary haemangioma & $7(8 \%)$ & 0 \\
Cavernous haemangioma & & \\
\hline
\end{tabular}

uncertain were not included in the study. The distribution and the size of the vascular malformations are summarised in Table 2 .

Other non-vascular lesions were detected coincidentally in eight patients - that is, colonic polyps in five, severe haemorroids in one, colonic varices in one, and malignant stomach ulcer in one patient.

\section{TREATMENT MODALITIES}

Photocoagulation of the lesion was carried out by means of a Neodymium Yag laser (Medilas MBB). The power was transmitted through a flexible fibre with coaxial $\mathrm{CO}_{2}$ jet, with a divergence angle of $\pm 10^{\circ}$. The fibre was introduced through the biopsy channel of the GIF-Q or XGIF-2T panendoscope (Olympus) or the CF-IB colonoscope (Olympus). A power of 65-80 Watt was used in short laser pulses of $0.5 \mathrm{sec}$, delivering a pulse energy of 35-40 joules to the tissue. The distance of the fibre tip from the tissue was kept constant at about $1 \cdot 5-2 \mathrm{~cm}$. Each laser pulse caused whitening of a well defined irradiated area. The next pulse was then delivered beside this coagulated area until all vascular tissue had disappeared. To treat large angiomas up to 15 pulses were occasionally necessary. If bleeding occurred during treatment, photocoagulation was continued in the same manner. The bleeding always ceased during treatment.

When lesions were large or numerous in the upper gastrointestinal tract, they were treated in repeated sessions. In the colon, however, numerous and large lesions were treated in one session whenever possible, in order to avoid repeated colonoscopies. In the course of the study it became obvious that, especially in patients with numerous lesions, a number of lesions were missed at the first therapeutic endoscopy. Therefore, a follow up endoscopy with laser treatment was carried out after one week in order to check the result of treatment. It was also soon observed that the lesions did not always disappear completely with the first course of treatment and angiomatous malformations may persist at the rim of the lesions necessitating a second treatment session.

\section{METHODS OF FOLLOW UP}

All but 10 patients had a clinical follow up at regular intervals. A check endoscopy was undertaken one to two months after initial therapy in 31 patients. If residual lesions were found these were treated. A check endoscopy was also carried out in 15 of the 17 patients with recurrent bleeding. The effect of laser therapy was evaluated using the following criteria: (1) The immediate results of laser therapy were evaluated by comparing the number of bleeding 
Table 2 Size and localisation of the vascular malformations treated by Yag photocoagulation

\begin{tabular}{|c|c|c|c|c|c|c|c|}
\hline \multirow[b]{2}{*}{ Size $(\mathrm{mm})$} & \multicolumn{7}{|l|}{ Location } \\
\hline & Oesophagus & Stomach & Duodenum & Jejunum & Ileum & Colon & Total \\
\hline$<10$ & 1 & 170 & 62 & 13 & 3 & 190 & 439 \\
\hline $10-20$ & - & 3 & 3 & - & - & 25 & 31 \\
\hline$>20$ & - & 2 & 1 & - & - & 9 & 12 \\
\hline Total & 1 & 175 & 66 & 13 & 3 & 224 & 482 \\
\hline
\end{tabular}

episodes and the number of units of blood transfused per patient for the month preceding laser therapy with the same parameters for the month after therapy. (2) For the analysis of long term results of laser therapy, other criteria had to be used, because precise data on the number of bleeding episodes and transfusions were not always available for long periods before laser. In fact, many patients were referred from other hospitals to our department for treatment. We therefore compared the number of months, for each patient during which he or she had presented with bleeding, considering an equally long period before and after therapy. The same analysis was carried out for transfusion data.

For each patient a bleeding ratio (number of months of bleeding per number of follow up months) and a transfusion ratio was defined for an equally long period before and after therapy. In this manner these paired data could be analysed by paired $t$ statistics. Disappearance of the lesions at check endoscopy and morbidity caused by laser therapy were also taken into account. For patients in whom laser therapy was unsatisfactory, a follow up period was included, which lasted until another therapy - for example, surgery, was carried out.

\section{HISTOLOGICAL STUDIES}

In six patients, three with gastric angiomas and three with colonic angiomas, the evolution of the lesions treated by laser was followed by repeated endoscopies with forceps biopsies before therapy, three to seven days, two weeks and one month after treatment in order to study the effect of laser photocoagulation on the angiomatous and surrounding tissue.

Biopsies were fixed in neutral formalin, embedded in paraffin and semiserially sectioned. Haematoxylin-eosin, periodic acid Schiff, and Masson's trichrome staining for fibrinogen were done. In the patients in whom surgery was carried out, the surgical specimen was carefully examined macroscopically and multiple biopsies for light microscopy were taken.

\section{Results}

In the 59 patients 482 vascular malformations were treated. The follow up period after treatment averaged 11.5 months (range 1-48 months). Recurrence of bleeding occurred in 17 of 57 patients available for follow up $(30 \%)$. All patients with Weber-Osler-Rendu syndrome had recurrence of bleeding after laser therapy as well as all patients with angiomas associated with coagulation disorders due to Von Willebrand's disease. Rebleeding occurred in nine of the 49 patients with angiodysplasia $(18 \%)$ included in the follow up (two of the 51 patients were operated upon).

Follow up data were available for 57 patients. The number of bleeding episodes per patient was $1.09 \pm 0.6($ mean $\pm S D)$ and the number of red blood cells units per patient in the month before therapy amounted to $2 \cdot 4 \pm 2 \cdot 6$. In the month following therapy these figures were $0 \cdot 16 \pm 0.6$ and $0 \cdot 21 \pm 0 \cdot 8$ respectively. These reductions in bleeding incidence and transfusion requirements were highly significant $(\mathrm{p}<0.001)$ (Fig. 1).

Comparison of bleeding ratio and transfusion ratio per patient before and after therapy at six, 12, 18 , and 24 months, indicates that the bleeding rate was significantly decreased for all follow up periods except at 24 months. (Fig. 2).

The influence of laser treatment on the incidence of gastrointestinal bleeding in relation to the site of the lesions is summarised in Table 3. The relation with the number of lesions treated is documented in Table 4. In patients with a limited number of angiomas 1-5 the lesions usually disappeared completely (18 of 21 patients with follow up at two months presented no lesions). With increasing numbers of lesions (number greater than five lesions), a greater number of lesions was missed at the first therapeutic endoscopy. (One of 10 patients had no lesions at control endoscopy.)

Recurrences of bleeding were caused by lesions missed or incompletely treated in nine patients, and by recurrent lesions in six patients. The origin was unknown in the two patients who did not consent with follow up endoscopy. 


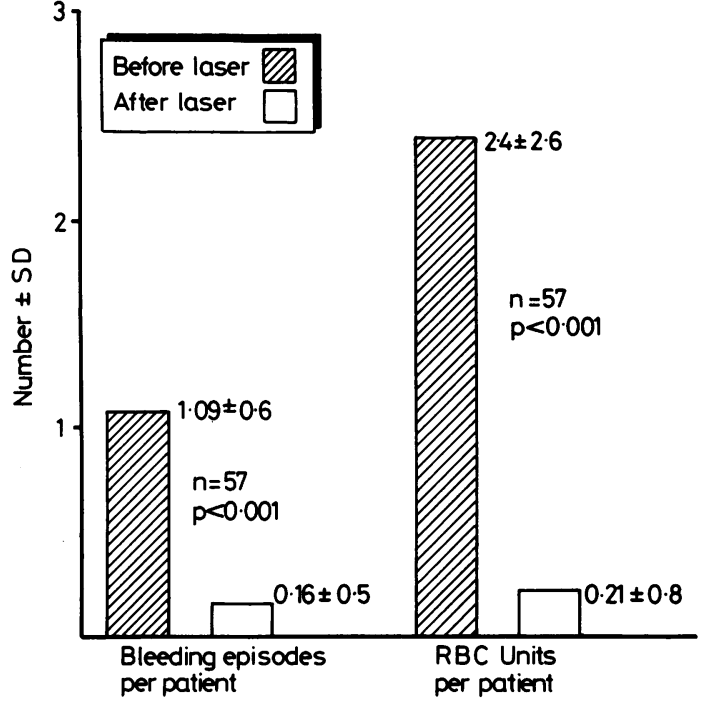

Fig. 1 Short term results of laser therapy in 57 subjects with bleeding from gastrointestinal vascular malformations: number of bleeding episodes and number of red blood cells units transfused in the month after therapy as compared with these parameters in the month preceding laser.
Seven patients had to be treated surgically. Pertinent data are summarised in Table 5.

Important complications of laser treatment occurred in six patients $(10 \%)$ (Table 6$)$. The most frequent complication was perforation (free gas), which occurred in two elderly patients with extensive angiodysplasia (numerous lesions and lesions measuring up to $3 \mathrm{~cm}$ ). These two patients with perforation were operated upon. One patient with a penetrating laser ulcer (peritonism - no free gas) was treated successfully by conservative means. One patient with Osler-Rendu syndrome, in whom a large duodenal angioma (diameter of more than 3 $\mathrm{cm}$ ) was treated by four laser sessions, developed an ulcer which took five months to heal under cimetidine. None of the patients died as a result of laser therapy. Three patients died by intercurrent diseases (cerebrovascular accident, respiratory failure, and bladder cancer). Endoscopic observations of laser induced lesions one week after treatment always showed ulcers with regular border surrounded by a slightly raised hyperaemic zone. The ulcer crater was covered with whitish slough. Ulcers on gastric folds were frequently irregular in shape, while ulcers in antrum, duodenum, and colon were mostly round or oval. Six patients were studied

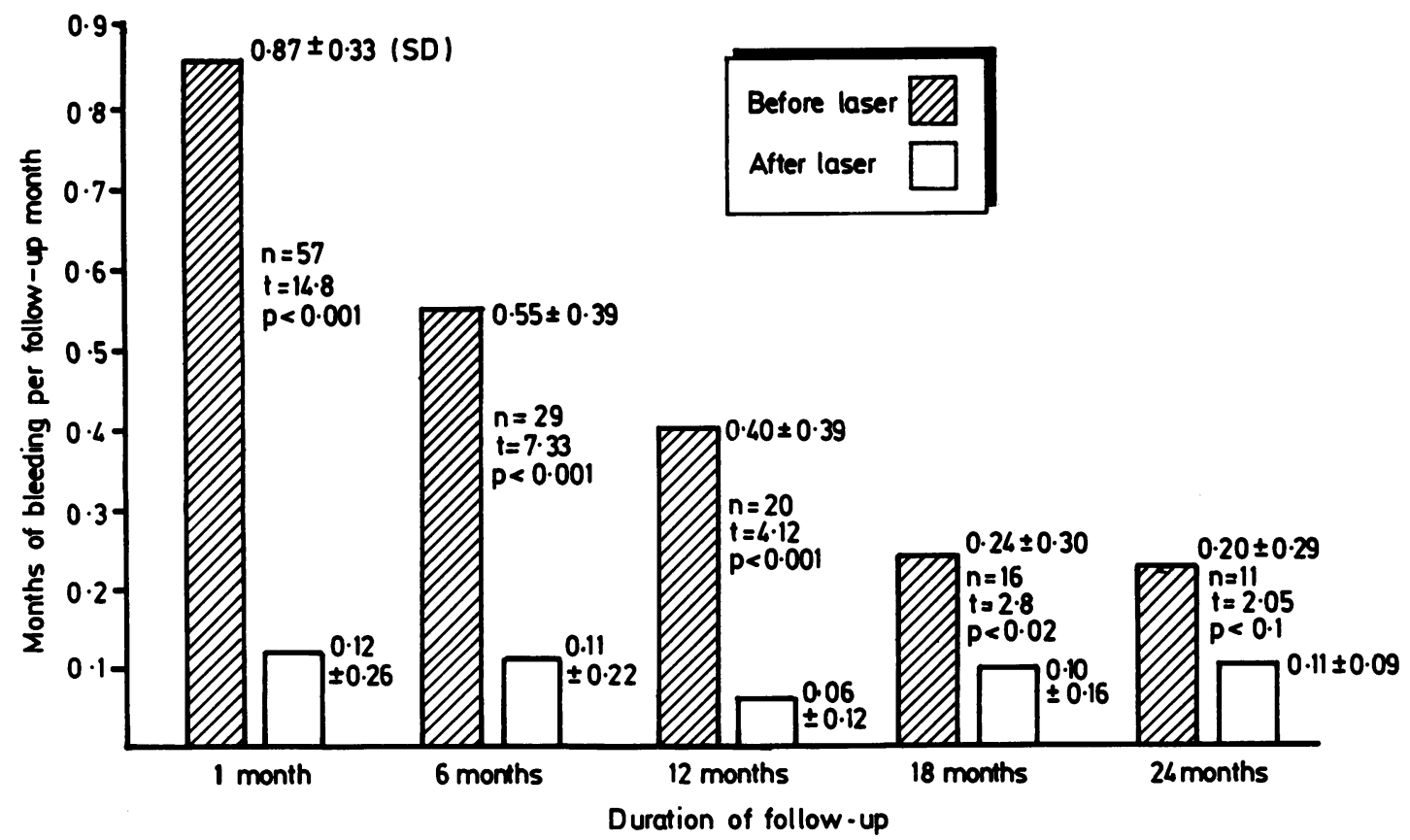

Fig. 2 Bleeding rates expressed as average bleeding months per months of follow up $\pm S D$ related to the duration of follow up in months. 
Table 3 Long term results of Neodymium Yag laser treatment of GI angiomas (mean follow up 11.5 months): relation to the location of the lesions

\begin{tabular}{|c|c|c|c|c|c|}
\hline \multirow[b]{2}{*}{ Localisation } & \multirow[b]{2}{*}{ Patients (no) } & \multirow[b]{2}{*}{ Lesions ( $M$, range) } & \multirow[b]{2}{*}{ Sessions $(M$, range $)$} & \multicolumn{2}{|c|}{ Months of bleeding per patient month } \\
\hline & & & & Before lase & After laser \\
\hline Upper GI tract & 25 & $10(1-80)$ & $2 \cdot 5(1-16)$ & $0 \cdot 26$ & $\begin{array}{r}0.09 \\
p<0.01\end{array}$ \\
\hline Lower tract & 29 & $6(1-25)$ & $1 \cdot 5(1-3)$ & 0.42 & $\begin{array}{r}0.14 \\
\mathrm{p}<0.001\end{array}$ \\
\hline Upper + lower tract & 3 & $24(3-39)$ & $4(3-5)$ & 0.90 & 0 \\
\hline
\end{tabular}

at two weeks. None of the gastric lesions had completely healed macroscopically although the lesions had become much smaller. Important hyperaemia was always present around all lesions. Colonic lesions had completely healed. In two of the three patients studied at two weeks only a white scar remained at the site of previous ulcers.

Histologically Yag laser photocoagulation caused thermal destruction of the mucosal and submucosal vascular malformation, and resulted in mucosal ulceration in the days after therapy. Biopsies taken three to seven days after laser treatment in the stomach showed an ulcer within the base of the

Table 4 Long term results of Neodymium Yag laser treatment of GI angiomas (mean follow up 11.5 months): relation to the number of lesions

\begin{tabular}{|c|c|c|c|c|}
\hline \multirow{3}{*}{$\begin{array}{l}\text { Lesions } \\
\text { (no) }\end{array}$} & \multirow{3}{*}{$\begin{array}{l}\text { Patients } \\
\text { (no) }\end{array}$} & \multicolumn{3}{|c|}{ Patients with months of bleeding } \\
\hline & & \multirow[b]{2}{*}{ Recurrence } & \multicolumn{2}{|c|}{ Per patient month } \\
\hline & & & Before laser & After laser \\
\hline $1-5$ & 31 & 5 & $\begin{array}{l}0.61 \\
T=6.01\end{array}$ & $\begin{array}{c}0.06 \\
p<0.001\end{array}$ \\
\hline $6-10$ & $15^{*}$ & 6 & $\begin{array}{l}0.52 \\
T=4.34\end{array}$ & $\begin{array}{c}0.04 \\
p<0.001\end{array}$ \\
\hline$>10$ & 11 & 6 & $\begin{array}{r}0.71 \\
\mathrm{~T}=3.13\end{array}$ & $\begin{array}{c}0.44 \\
\mathrm{p}<0.01\end{array}$ \\
\hline
\end{tabular}

* one excluded ulceration fibrous tissue in which vessels occluded by recent thrombus could be seen. Traces of re-epithelialisation became apparent at this time. In the mucosa adjacent to the ulcer dilated glands, lined by atypical epithelial cells were present. Mitoses were plentiful in these regenerating glands. Later after treatment, large zones of reepithelialisation were seen. The mucosa was atrophic and consisted of a single layer of epithelial cells, without glands. At two weeks none of the three patients with stomach ulcer showed complete re-epithelialisation. After one month the mucosa showed some irregular glands, resting on fibrous tissue.

Biopsies taken in the colonic lesions early after laser photocoagulation showed coagulation necrosis of the mucosa and part of the submucosa with destruction of the vessels immediately beneath the area of necrosis. After two weeks two out of three patients with colonic lesions had healed completely. In colonic biopsies obtained in these patients the mucosa was covered by a single layer of epithelium. It must be emphasised that comparison of healing rates was not always possible as the size of the laser ulcers was not always identical.

From operative specimens it was apparent that the abnormal vessels are destroyed only in the efficiently treated area. Surrounding vessels stay open as can be seen in Fig. 3 from a patient treated for angiodysplasia.

Table 5 Operative procedures in seven patients with vascular malformations treated by laser

\begin{tabular}{llllrl}
\hline Patients & Diagnosis & Procedure & Indication postoperative & Follow up (months) & Rebled \\
\hline BJ & Osler-Rendu & Total gastrectomy & Bleeding & 21 & - \\
VJ & Angiodysplasia & B II gastrectomy & Malignant ulcer & 1 & - \\
AE & Osler-Rendu & B II gastrectomy & Bleeding & 23 & - \\
MJ & Von Willebrand & Partial jejunectomy & Bleeding & 3 & + \\
VM & Osler-Rendu & Segmental ileocolectomy & Bleeding & 7 & + \\
CC & Angiodysplasia & Right hemicolectomy & Perforation & 1 & - \\
NJ & Angiodysplasia & Right hemicolectomy & Perforation & 1 & - \\
\hline
\end{tabular}


Table 6 Complications of laser therapy of vascular malformations of the GI tract

\begin{tabular}{ll}
\hline Complication & Patients (no) \\
\hline Severe pain during treatment & 1 \\
Chronic duodenal ulcer & 1 \\
Acute severe bleeding after laser & 1 \\
Caecal perforation & 1 \\
$\begin{array}{l}\text { Free caecal perforation with contiguous lesion of } \\
\text { the adjacent small bowel }\end{array}$ & 1 \\
Perforation treated conservatively & 1 \\
Total & $6(10 \%)$ \\
\hline
\end{tabular}

\section{Discussion}

This study indicates that Neodymium Yag laser photocoagulation of gastrointestinal angiomas, significantly decreases the rate of bleeding but does not eliminate it completely. The short term reduction of bleeding rates and transfusion requirements are impressive. The long term results of laser treatment are not related to the location of the lesions; both gastric and colonic lesions can be treated with equal efficiency. More important for the outcome, however, is the number of lesions. The more numerous the lesions the less efficacious laser photocoagulation is in decreasing the rate of bleeding. Rebleeding originates mostly from lesions missed or incompletely treated at therapeutic endoscopy. Another important obsevation is that treatment is unsuccessful in the Weber-Osler-Rendu syndrome where the extent of the disease is rarely accurately assessed, and in patients with angiomas associated with Von Willebrand's disease probably the result of coagulation disorders. Laser treatment was most efficacious in patients with angiodysplasia; $82 \%$ of these patients had no recurrence during the follow up period.

Yag laser photocoagulation produces necrosis of the vascular tissue, even in the submucosa, shortly after application of the laser beam. ${ }^{13}$ If photo-

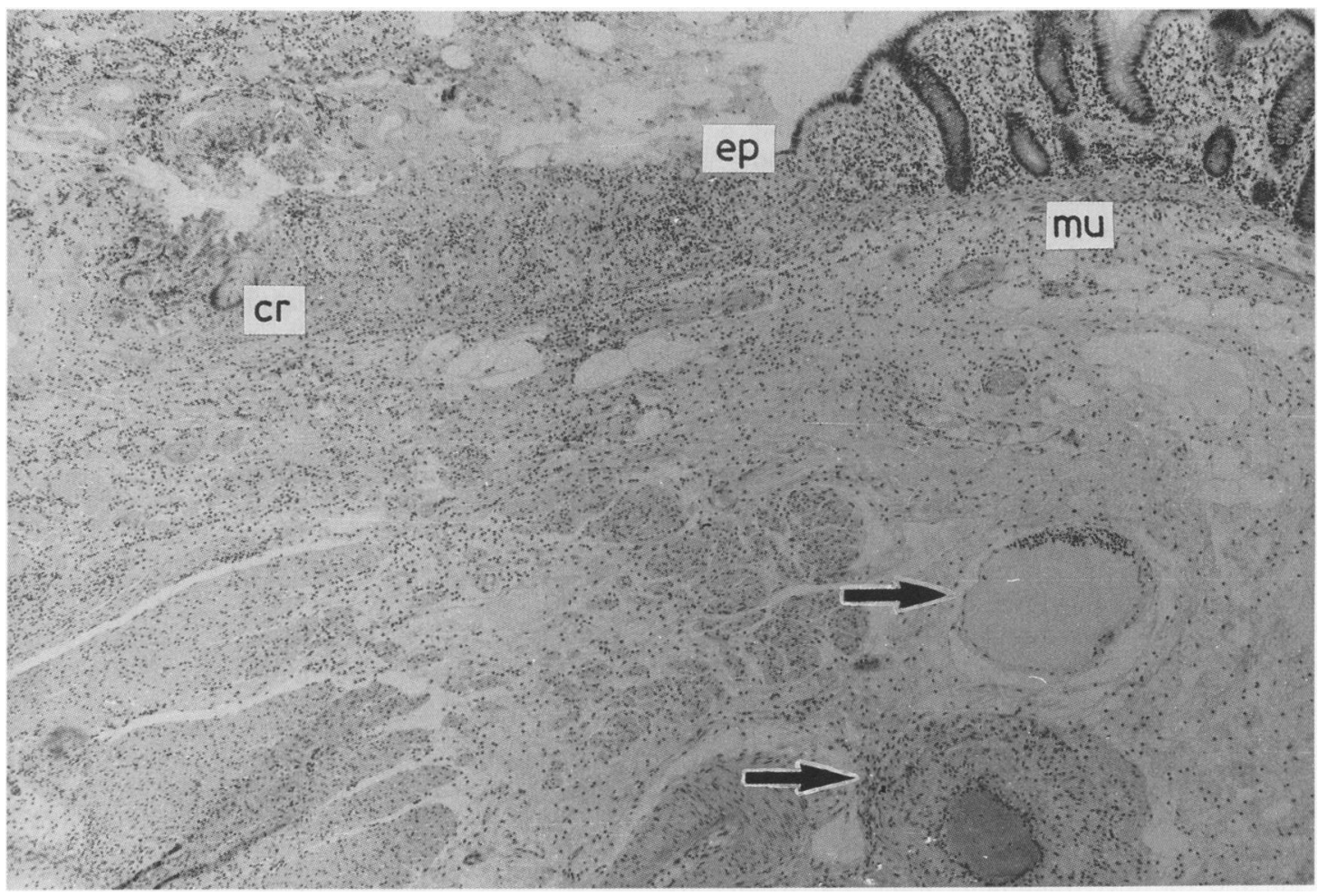

Fig. 3 Angiodysplasia of the colon after laser photocoagulation (surgical specimen): re-epithelialisation (ep) starting at the edge of the ulcer. In the ulcer base granulation tissue is present together with some remaining crypts (cr). Underneath the normal mucosa (mu), in the submucosa some blood vessels, undamaged by the photocoagulation are still present (arrows). These vessels may be responsible for recurrent bleeding ( $\mathrm{HE} \times 50$ original magnification). 
coagulation produces an immediate mucosal defect bleeding occurs, but this is usually mild. Laser treatment is always followed by mucosal ulceration after a few hours or days. The deep damage caused by photocoagulation heals by fibrosis and the lesion is covered by an atrophic epithelium. The vascular tissue is destroyed only in the area in which enough energy-density is built up by laser photocoagulation. Even with effective destruction of the centre of an angioma, the vascular spaces may stay open at the rim. The optimal power and duration of irradiation in relation to effect and tissue damage have been determined for Argon laser and electrocoagulation ${ }^{14}$ but are still unknown for Yag laser photocoagulation in the colon. The wall of the human colon is only half as thick as that of the stomach wall. When large lesions are to be treated completely, a great number of laser pulses is needed, thereby increasing the risk for perforation.

Another important factor that has to be taken into account is the fact that these lesions occur in a colonic wall of normal thickness. This is in sharp contrast with a severely bleeding chronic ulcer with a thickened inflammatory and fibrotic base. These features explain the high perforation rate $(6 \%)$ in this study of Yag laser treatment of colonic angiodysplasia as compared with a perforation rate of $1 \%$, reported in Yag treatment of bleeding peptic ulcers. In our own experience ${ }^{15} 16$ with more than 200 patients treated by Yag laser for upper gastrointestinal bleeding, free perforation was never observed. Therefore extensive caecal vascular malformations should be treated cautiously. The total energy applied to each lesion should probably not exceed 200 joules and should certainly be less than the 600 joules we used in some lesions. Important bleeding following Yag laser therapy of vascular malformations has been reported ${ }^{10}$ and occurred in one of our patients, although a conservative management was successful. The slower healing of gastroduodenal laser ulcers as compared with colonic ulcers is probably the result of exposure to acid-pepsin. Pretreatment of the patients with oral prostaglandins ${ }^{17}$ may speed up the healing and may even avoid the evolution to chronic ulcer, observed in one of our patients.

Our results indicate that in the majority of patients with vascular malformations of the gastrointestinal tract, Yag laser photocoagulation may be the method of choice for eliminating or reducing bleeding risk. Angiodysplasia is the lesion most suitable for this treatment, while the results are disappointing in Osler-Weber and Von Willebrand's disease. In patients with extensive lesions in the right colon, repeated treatments with application of energy densities of up to 200 joules per lesion, are advocated because the risk of perforation will certainly be less than one with complete treatment in a single session.

\section{References}

1 Richardson JD, Max MH, Flint LM Jr, Schweisinger W, Howard M, Aust JB. Bleeding vascular malformations of the intestine. Surgery 1978; 84: 430-4.

2 Baum S, Athanatoulis CA, Waltman AC, et al. Angiodysplasia of the right colon: a cause of gastrointestinal bleeding. Am J Roentgenol 1977; 129: 789-95.

3 Boleẏ SJ, Sammartano R, Brandt LJ, Sprayregen S. Vascular ectasias of the colon. Surg Gynecol Obstet 1979; 149: 353-9.

4 Sinderman KW, Franklin J, Sos TA. Successful transcatheter gelfoam embolisation of a bleeding vascular ectasia. Am J Roentgenol Rad Ther Nucl Med 1978; 131: 157-9.

5 Weingart J, Elster K, Ottenjann R. Recurrent gastrointestinal bleeding in Osler's disease successfully treated by endoscopic electrocoagulation in the stomach. Endoscopy 1975; 7: 160-4.

6 Rogers BHG, Adler F. Hemangiomas of the cecum. Colonoscopic diagnosis and therapy. Gastroenterology 1976; 71: 1079-82.

7 Howard OM, Buchanan JD, Hunt RM, Mc Carter. Angiodysplasia of the colon. Lancet 1982; 2: 16-9.

8 Jensen DM, Machicado GA, Tapia JI et al. Endoscopic treatment of hemangiomata with Argon laser in patients with gastrointestinal bleeding. Gastroenterology 1982; 82: 1093.

9 Bowers JH, Dixon JA. Argon laser photocoagulation of vascular malformations of the GI tract: short term results. Gastrointestinal Endosc 1982; 28: 126.

$10 \mathrm{Johnston} \mathrm{JH.} \mathrm{Complications} \mathrm{following} \mathrm{endoscopic} \mathrm{laser}$ therapy. Gastrointest Endosc 1982; 28: 2: 135.

11 Young W, Gilbert V, Feinstat T, Trudeau W. The recurrent upper gastrointestinal bleeding in hereditary hemorrhagic relangietasia (Osler's disease) successfully treated by endoscopic sclerotherapy. Gastrointest Endosc 1982; 28: 2: 148.

12 Moore JD, Thompson NW, Appelman HD. Arteriovenous malformations of the gastrointestinal tract. Arch Surg 1976; 111: 381-9.

13 Etienne J, Dorme N, Ladouch-Badre A, Raimbert P, Berthier JP, Sultan R. Comparative study of the effects of argon and Neodymium Yag laser beams on the normal fundic wall in the beagle dog. Dig Dis Sci 1982; 27: 425-33.

14 Jensen DM, Machicado GA, Tapia JI, Maritner W. Comparison of Argon laser photocoagulation and bipolar electrocoagulation for endoscopic hemostasis in the canine colon. Gastroenterology 1982; 83: 830-5.

15 Rutgeerts P, Vantrappen G, Broeckaert L et al. Controlled trial of Yag laser treatment of upper 
digestive hemorrhage. Gastroenterology 1982; 83: 410 6.

16 Rutgeerts P, Vantrappen G, Geboes K, Broeckaert L. Neodymium Yag laser photocoagulation for haemostasis of gastrointestinal non-variceal hemorrhage. $Z$
Gastroenterol 1983; 21: 263-7.

17 Geboes K, Rutgeerts P, Vantrappen G, Desmet VJ. The influence of 15 (R) 15 Methyl $\mathrm{PGE}_{2}$ on Nd Yag laser induced gastric ulcers. Gastrointest Endosc 1984; 30: $173-8$. 